\title{
Internal Carotid Artery Aneurysms Presenting with Epistaxis - Our Experience and Review of Literature
}

\author{
Kanwaljeet GARG, Hitesh Kumar GURJAR, Pankaj Kumar SINGH, Manmohan SINGH, P Sarat CHANDRA, \\ Bhawani Shankar SHARMA
}

All India Institute of Medical Sciences, Department of Neurosurgery, New Delhi, India

\section{ABSTRACT}

\begin{abstract}
AIM: Intracranial internal carotid artery aneurysms are an extremely rare cause of spontaneous epistaxis, with a few documented cases. The management of such cases is challenging due to the relative anatomical inaccessibility of the bleeding point. The aim of the present study was to acquaint the readers with this rare type of aneurysm presenting with epistaxis and to report our experience of treating cases of severe epistaxis due to internal carotid artery (ICA) aneurysms.
\end{abstract}

MATERIAL and METHODS: Data of 4 patients with ICA aneurysms presenting with epistaxis from June 2011 to July 2013 was retrospectively reviewed.

RESULTS: The age of patients ranged from 16 to 62 years. Duration of epistaxis ranged from 3 months to 3 years. Two patients had severe epistaxis following transnasal biopsy. Two patients had a history of trauma. Two patients developed hemodynamically instability. All the patients were managed with trapping of the aneurysm. Complete exclusion of aneurysm from circulation was achieved in all the patients.

CONCLUSION: ICA aneurysms can rarely present as life-endangering epistaxis. In patients presenting with a history of craniocerebral trauma, traumatic pseudoaneurysm must be considered as a differential diagnosis. Trapping of the aneurysm is a good option if there is good cross circulation.

KEYWORDS: Aneurysm, Pseudoaneurysm, Epistaxis, Trapping, Cross circulation

\section{INTRODUCTION}

Aneurysms of the internal carotid artery (ICA) can be a source of massive and life-threatening epistaxis $(6-8,12,13,15,18,21$, 27). True carotid aneurysms, with sphenoid extension and revealed by epistaxis, are rare. The majority of these aneurysms are pseudoaneurysms that are related to traumatic, congenital, mycotic, and inflammatory causes $(1,12)$. A pseudoaneurysm or false aneurysm usually develops following an injury, involving all 3 layers of the arterial wall. Later, a fibrous capsule develops from the surrounding perivascular connective tissue and surrounds the extravasated blood. As the aneurysm expands, it ruptures, eventually resulting in massive hemorrhage.
Intraarterial digital subtraction angiography is the diagnostic modality of choice. The management of such cases is challenging due to the relative anatomical inaccessibility of the bleeding point. Management depends on the status of cross circulation. If the cross circulation is adequate, carotid sacrifice (either endovascular or surgical) is a treatment option and if it is inadequate, one is left with the options of either extracranial intracranial bypass or selective embolization of the pseudoaneurysm. We studied 4 such cases, managed surgically at our center.

\section{MATERIAL and METHODS}

From June 2011 to July 2013, 4 patients underwent treatment 
Garg K. et al: Internal Carotid Artery Aneurysms with Epistaxis

for ICA pseudoaneurysms presenting as intractable epistaxis in our hospital. We retrospectively reviewed their medical records.

\section{Case 1}

A 32-year-old male patient presented to an otolaryngologist with complaints of repeated episodes of epistaxis for last 3 years. He was thought to have some sinonasal mass lesion and underwent endoscopic nasal biopsy. Biopsy was suggestive of benign mesenchymal cells. Two weeks after biopsy, the patient had massive epistaxis and was referred to our centre. A vascular etiology was suspected and intra-arterial digital subtraction angiography (IADSA) was done. It revealed large partially thrombosed dissecting aneurysm, involving the right ICA distal to the $\mathrm{C} 2$ segment along with a pseudoaneurysm, measuring $9.6 \times 5.7 \mathrm{~mm}$, projecting anteromedially into sphenoid sinus. The cross compression study revealed good flow through the anterior communicating artery (AComA) and right posterior communicating artery ( $\mathrm{PComA})$. The patient was planned for trapping of the aneurysm as there was good cross circulation. He underwent ligation of the right ICA in the neck, and craniotomy and clipping of the right ICA proximal to PComA. IADSA after surgery revealed complete exclusion of the aneurysm from circulation with good filling of the middle cerebral and anterior cerebral artery territories through AComA and PComA. At 2 year follow up, the patient is asymptomatic.

\section{Case 2}

A 39-year-old male patient was involved in a road traffic accident 6 months back, following which he gradually developed progressive, painless loss of vision in right eye and repeated episodes of epistaxis. Computed tomography was done and it revealed a soft tissue mass filling the sphenoid sinus and bilateral posterior ethmoids along with destruction of bone (Figure 1A-C). Magnetic resonance imaging (MRI) revealed a lesion in sphenoid sinus and posterior ethmoids, which was hypointense on T1WI and hyperintense on T2WI. He underwent transnasal biopsy from the lesion, which was followed by profuse epistaxis. He underwent nasal and nasopharyngeal packing in order to stop the bleeding and the patient was referred to us. We did an IADSA, which revealed a multilobed small neck pseudoaneurysm, $5 \times 4.5 \mathrm{~cm}$ in size, arising from the right paraopthalmic and cavernous ICA junction (medial wall) and projecting into sphenoethmoidal sinus. The fundus of the aneurysm was directed medially, downwards and anteriorly. The right $A 1$ was hypoplastic with right $\mathrm{A} 2$ filling through $\mathrm{AComA}$. Cross compression studies revealed slight cross flow. As the cross flow did not appear to be adequate, he was planned for ECA to ICA bypass next day morning. During the night, he developed profuse epistaxis and became hemodynamically unstable. He was shifted to the operating room and the right ICA was ligated. The epistaxis stopped and he was stabilized hemodynamically. IADSA after the ligation of ICA showed retrograde filling of the ICA till the petrous segment, and flow in the right MCA and ACA territory through PComA and AComA. He did not have weakness in the left extremities. He underwent right pterional craniotomy and clipping of right ICA proximal to PComA. However, the ophthalmic artery could not be identified. The patient was discharged from the hospital in a stable condition. He did not have any further episode of epistaxis and is asymptomatic at 1 month follow up.

\section{Case 3}

A 62-year-old male patient presented to us with history of repeated episodes of epistaxis for the last year. IADSA revealed left ICA laceral segment dissecting pseudoaneurysm measuring $3.7 \times 2 \times 2 \mathrm{~cm}$ with a neck of size $1.3 \mathrm{~cm}$, projecting into the sphenoid sinus (Figure $2 \mathrm{~A}-\mathrm{C}$ ). The aneurysm was multilobed and was directed anteriorly. On cross compression, there was good cross flow. The patient underwent ligation of left ICA. He developed transient dysphasia and right-sided weakness, which resolved in few hours on its own. The patient was planned for left superficial temporal artery to MCA bypass to augment circulation. IADSA was repeated, and revealed complete exclusion of the aneurysm from the circulation. The patient is free of epistaxis at 8 months follow-up.

\section{Case 4}

A 16-year-old male patient was involved in a road traffic accident and was managed conservatively for left temporal extradural hematoma. Three months after the accident he presented to us with gradually progressive proptosis in the left eye, associated with visual diminution in the same eye. There was non axial proptosis in the left eye and he could not perceive light in his left eye. The rest of the physical and neurological examination was normal. The clinical impression was carotico-cavernous fistula (CCF) and IADSA was planned. It revealed a large left CCF with a rent in the anterior genu of the left cavernous ICA with giant pseudoaneurysm formation, $27 \times 23 \times \mathrm{mm}$ with extension into the left sphenoid sinus (Figure $3 A, B)$. It was draining into the left superior ophthalmic vein. There was complete steal in the fistula with no flow in the left ACA and MCA on left ICA injection. There was good cross flow to the left MCA, ACA and supraclinoid ICA from the right ICA and vertebral arteries. The patient was planned for embolization and was waiting for funds to be arranged. In the meantime, the patient developed profuse epistaxis. He underwent emergent left ICA ligation. Repeat IADSA revealed retrograde filling of aneurysm through AComA and external carotid artery (ECA). He underwent craniotomy and ICA was ligated proximal to PComA. As there was filling of the aneurysm through the ECA, it was also ligated. Repeat IADSA was done and revealed complete exclusion of the aneurysm from the circulation. The patient is asymptomatic at 2 months follow up.

\section{RESULTS}

The results and follow-up findings are listed in Table I. All four patients were male with ages ranging from 16 to 62 years. They all presented with epistaxis, and three patients had recurrent episodes of epistaxis. The duration of epistaxis ranged from 3 months to 3 years. Two patients had severe epistaxis following transnasal biopsy. Two patients had diminution of vision. One patient had proptosis due to associated CCF. Two patients had a history of trauma (Table I). 

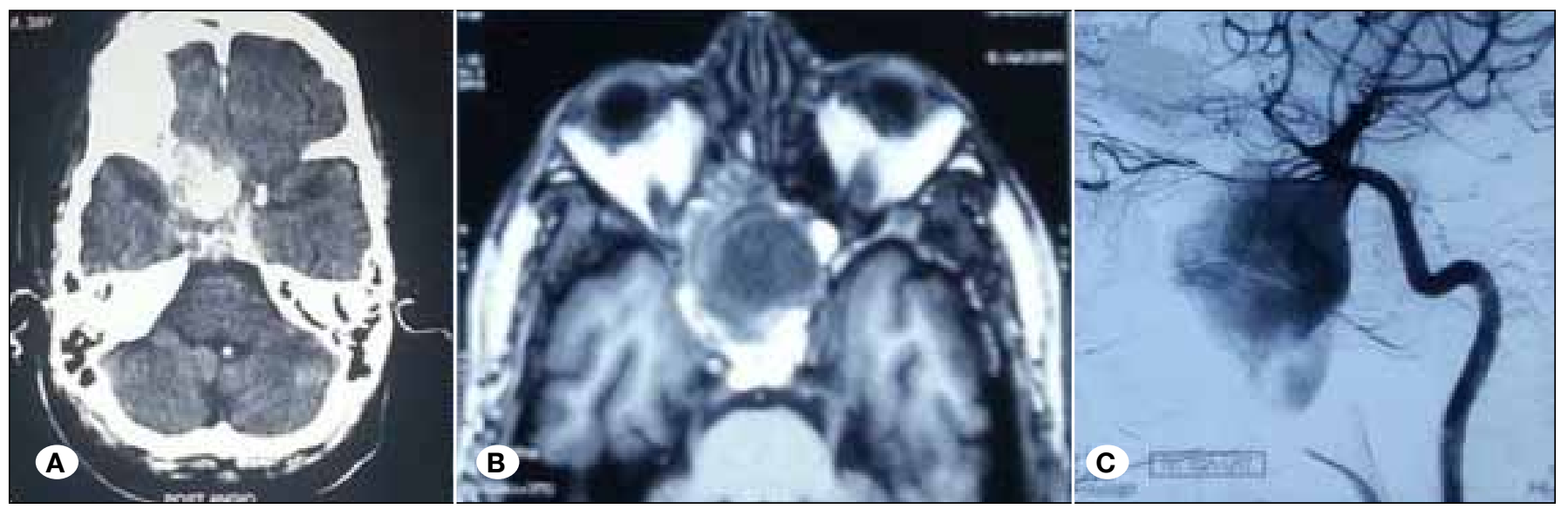

Figure 1: A) Post digital subtraction angiography head showing a contrast-enhancing lesion in the suprasellar region with erosion of surrounding bone, B) T2 WI MRI axial sections showing hypointense lesion in suprasellar region, C) IADSA AP and lateral view on right ICA injection showing multilobed small neck pseudoaneurysm arising from the right paraopthalmic and cavernous ICA junction and projecting into sphenoethmoidal sinus.
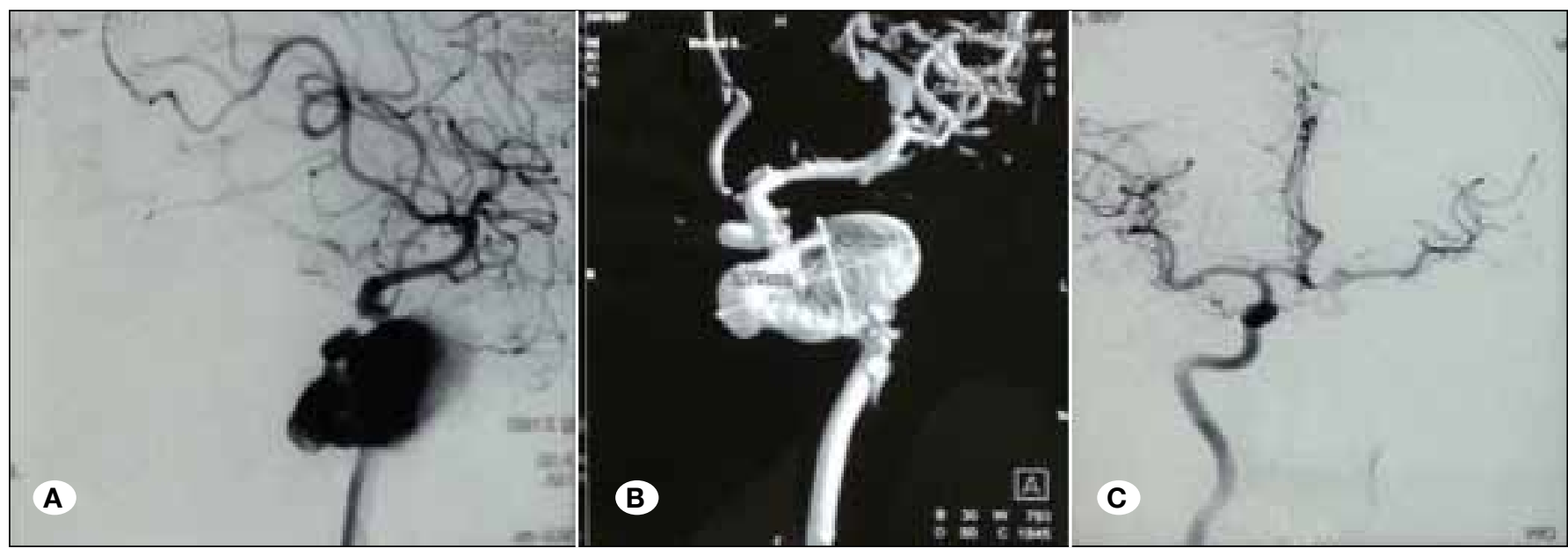

Figure 2: A) IADSA left ICA injection lateral view showing multilobulated left ICA laceral segment dissecting pseudoaneurysm measuring $3.7 \times 2 \times 2 \mathrm{~cm}$ with neck of size $1.3 \mathrm{~cm}$, projecting into sphenoid sinus, B) IADSA 3 D reconstruction images showing the left ICA pseudoaneurysm, C) IADSA AP view on right ICA injection with left ICA compression showing good cross flow.

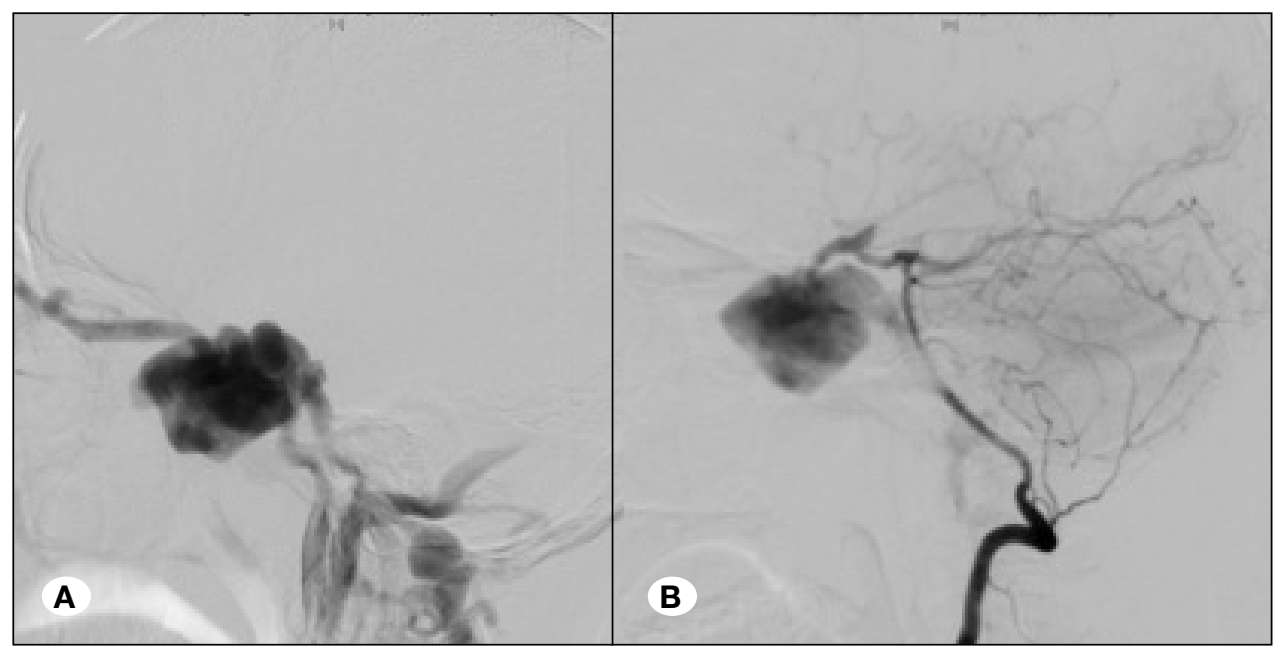

Figure 3: A) IADSA left ICA injection AP view showing large left CCF with rent in anterior genu of left cavernous ICA with giant pseudoaneurysm formation and there is no filling of MCA or ACA suggestive of complete steal in fistula, B) IADSA left ICA injection lateral view showing large left CCF with giant pseudoaneurysm formation, it is draining into left superior ophthalmic vein and there is complete steal in the fistula. 
All cases had previously been managed with conventional management procedures. Two patients developed hemodynamic instability during admission and had to go through resuscitation maneuvers and required multiple blood transfusions. IADSA was done in all of our patients. All the patients had origins of the pseudoaneurysms in the ICA along its $\mathrm{C} 2$ to $\mathrm{C} 4$ segment.

All the patients had good cross circulation as seen on cross compression in IADSA. All the patients were managed with trapping of the aneurysm. Complete exclusion of aneurysm from circulation was achieved in all the patients.

Table I: Description of Our Patients

\begin{tabular}{|c|c|c|c|c|}
\hline No & 1 & 2 & 3 & 4 \\
\hline $\begin{array}{l}\text { Predisposing event } \\
\text { for profuse epistaxis }\end{array}$ & $\begin{array}{l}\text { Biopsy (Benign } \\
\text { mesenchymal tissue) }\end{array}$ & Biopsy & None & Trauma \\
\hline Affected artery & $\begin{array}{l}\text { Right ICA (distal to } \\
\text { C2) }\end{array}$ & $\begin{array}{l}\text { Right ICA (C4 - C6 } \\
\text { segment) }\end{array}$ & $\begin{array}{l}\text { Left ICA (C3 } \\
\text { segment) }\end{array}$ & Left ICA (C4 segment) \\
\hline $\begin{array}{l}\text { Aneurysm } \\
\text { characteristics }\end{array}$ & $\begin{array}{l}9.6 \times 5.7 \mathrm{~mm} \text {, } \\
\text { thrombosed } \\
\text { dissecting } \\
\text { aneurysm projecting } \\
\text { anteromedially into } \\
\text { sphenoid sinus. } \\
\text { Good cross flow } \\
\text { through AComA and } \\
\text { PComA }\end{array}$ & $\begin{array}{l}50 \times 45 \mathrm{~mm} \text { (giant), } \\
\text { multilobed small } \\
\text { neck paraclinoid } \\
\text { pseudoaneurysm, } \\
\text { projecting into } \\
\text { sphenoethmoidal sinus. } \\
\text { Poor cross circulation } \\
\text { (Figure 1) }\end{array}$ & $\begin{array}{l}37 \times 20 \times 20 \mathrm{~mm} \\
\text { (giant), } \\
\text { Laceral segment } \\
\text { dissecting } \\
\text { aneurysm } \\
\text { projecting into } \\
\text { sphenoid sinus } \\
\text { (Figure 2) }\end{array}$ & $\begin{array}{l}27 \times 23 \mathrm{~mm} \text { (giant), } \\
\text { pseudoaneurysm extending } \\
\text { into sphenoid sinus. } \\
\text { Carotico-cavernous fistula } \\
\text { draining into left superior } \\
\text { ophthalmic vein with no } \\
\text { flow in left ACA and MCA } \\
\text { on left ICA injection. Good } \\
\text { cross flow to left from right } \\
\text { ICA and VA (Figure 3) }\end{array}$ \\
\hline
\end{tabular}

Trapping of aneurysm (ICA

Management ligation in neck and clipping proximal to PComA)
Trapping of aneurysm (ICA ligation in neck and clipping proximal to PComA)
Left ICA ligation and left STA MCA bypass
Left ICA ligation in neck
Repeat DSA showed retrograde filling through AComA and ECA. ECA ligation and proximal clipping of ICA

\begin{tabular}{lllll}
$\begin{array}{l}\text { Recurrent episode } \\
\text { and management }\end{array}$ & None & None & None & $\begin{array}{l}\text { AComA and ECA. } \\
\text { ECA ligation and proximal } \\
\text { clipping of ICA }\end{array}$ \\
\hline Follow up & 24 months & 1 month & 8 months & 2 months \\
\hline GOS at discharge & 5 & 4 & 5 & 5 \\
\hline $\begin{array}{l}\text { GOS at last follow } \\
\text { up }\end{array}$ & 5 & 5 & 5 & 5 \\
\hline
\end{tabular}




\section{DISCUSSION}

Epistaxis is a common ailment and is estimated that 7-60\% of the population experiences an episode of epistaxis during their lifetime (19). However it is usually only mild and does not require medical attention, and only $6 \%$ of patients with epistaxis will require medical help (20). Various causes of epistaxis include dryness of the nasal cavity, digital trauma to the nasal cavity, hypertension, anticoagulation, and blood dyscrasias $(7,12)$. Most of these cases are easily managed with local measures, such as applying pressure to the nostrils, chemical or electrocauterization, topical hemostatic or vasoconstricting agents, cryotherapy, hot water irrigation, together with the management of underlying risk factors such as hypertension and oral anticoagulation. Other less common causes of epistaxis include trauma and vascular abnormalities, and are usually associated with severe lifethreatening epistaxis (7).

ICA aneurysms with sphenoid extension and revealed by epistaxis are rare. Aneurysms that involve the cavernous segment of the ICA account for $3-5 \%$ of all intracranial aneurysms (10). Many of these aneurysms occur following trauma but post-operative and non-traumatic aneurysms have also been documented $(5,10)$.

All the 3 layers of vessel wall line true aneurysms, whereas in a pseudoaneurysm the aneurysm is not walled by true vessel wall but by a blood clot or fibrous wall. Pseudoaneurysm formation results from intimal tear as a result of trauma, which can be augmented by flowing blood. Weakening and enlargement from continuous pulsatile forces can result in breakdown of the fibrous wall and eventual rupture (7). Sometimes, there can be decreased blood flow and spontaneous intraluminal thrombus formation (24). Blunt trauma represents the cause for $3-10 \%$ of all ICA aneurysms (22). In 2 of our patients (Case $1,2)$, ICA pseudoaneurysms (ICA PA) were induced by biopsy from the giant ICA aneurysm, which was thought to be a sinonasal mass by the otolaryngologists in both cases. In one patient there was no history of trauma (Case 3). In the fourth case, the patient had history of trauma.

ICA PA usually results in florid symptoms, though occasional cases may be asymptomatic. The cavernous ICA has an intimate relationship with the sphenoid sinus, bulging into the lateral sinus wall in $71 \%$ of cadaveric dissections (25). The bony covering over the cavernous ICA within the sphenoid sinus was less than $1 \mathrm{~mm}$ in $66 \%$ of cases, and in $4 \%$ there was no bony covering (25). The thin interface of tissue between these structures makes this a site for potential injury in trauma and surgery of the sphenoid sinus $(7,12)$. ICA PA can rarely present as recurrent epistaxis, though most of them result in massive bleeding due to rupture into the sphenoid sinus $(4,5,7)$. Intracavernous ICA PA are in close anatomic proximity to other cavernous structures and thus may be associated with injury to cranial nerves II, III, IV, V1-2, and $\mathrm{VI}$, as well as the ophthalmic artery. Clinically, the finding of the classic symptomatic triad of unilateral blindness, orbital fractures, and massive epistaxis is almost pathognomonic for ICA PA $(7,12)$. Retro-orbital pain can also be present (11). One should be aware of these clinical features in ICA PA and an early detection and intervention can save the life of a patient. Otolaryngologists should consider a differential of ICA PA in patients having epistaxis following trauma, as they are the ones who are consulted first for epistaxis and they might end up trying transnasal biopsy from the lesion, the nature of which may not be clear on routine CT or MRI.

ICA PA resulting in epistaxis may present immediately after the trauma or the presentation may be delayed by weeks. Delayed epistaxis may be explained by the time necessary for the traumatic event to weaken the vessel wall and for pulsatile pressure to erode through any intact bone along the sphenoid sinus (15) and most cases usually presenting at about the third week (88\%) (7). The initial episodes of epistaxis may not be severe and the patient may neglect it and this may result in diagnostic and therapeutic delay (7).

IADSA is the diagnostic modality of choice. CT angiography or MR angiography may be helpful if IADSA is unavailable, but cross circulation can only be adequately assessed with IADSA. It is noteworthy that a transnasal biopsy should be avoided till a vascular pathology has been ruled out in patients presenting with epistaxis and having sellar suprasellar lesion on routine radiological imaging.

The management techniques have improved drastically over the past few decades, but theoretically we still have only two options: to preserve or to occlude the carotid artery. Treatment options depend on the status of the cross circulation. If the cross circulation is adequate, carotid sacrifice (either endovascular or surgical) is a treatment option. Anatomic constraints limiting operative exposure and distal control add up to the fact that direct clipping of the fragile lesion is by itself difficult to achieve, making a direct surgical approach to the cavernous and petrous ICA a very challenging issue (3). Surgical ligation or carotid artery occlusion can result in significant cerebrovascular events, even if the cross circulation is good, as was seen in one of our cases (9). After the ligation of the ICA, there is risk of developing collateral blood flow into the pseudoaneurysm leading to recurrent epistaxis $(7,10)$ and it was to prevent this complication that we clipped ICA proximal to the PComA in three patients.

Endovascular management of pseudoaneurysms is gaining considerable clinical recognition these days. A pseudoaneurysm can be excluded from the circulation while maintaining the patency of ICA with embolization with detachable coils or stent-assisted coils $(14,23)$. Lempert et al. (17) described successful direct coiling of eleven consecutive post traumatic pseudoaneurysms with preservation of the parent vessels. However, a pseudoaneurysm consists of only fibrous tissue and does not contain any of the normal vessel wall elements, making coiling difficult as there is no wall to confine the coils. Furthermore, owing to pseudoaneurysm's fragility, there is always a fear of rupture. Many such mishaps have been reported in literature $(17,28)$. Thus, direct tight coiling of the pseudoaneurysm is much more difficult than of a true aneurysm.

Whereas false aneurysms of the cavernous internal carotid (traumatic or infectious) are known and documented, true carotid aneurysms with sphenoid extension and revealed by 
epistaxis are rare (2). Lehman et al. reviewed literature and could find only 36 such cases from 1950 to 2006. (16) They found a mortality rate of $22.2 \%$ in these patients, emphasizing the severity of the condition. The mortality was very high in those who were not treated $(71.4 \%, 5$ out of 7 died). The treatment options used in various patients included no treatment (7 patients), surgery (14 ligatures of the affected vessel, 3 trappings and 4 clippings of the aneurysm) and endovascular treatment (2 sacrifices of the affected vessel by balloon, 6 selective treatments of the aneurysm by coil or balloon); 19 procedures were done by killing the affected vessel which is the therapeutic alternative after testing tolerance of clamping.

Zhang et al. (28) studied 14 consecutive patients with traumatic pseudoaneurysms presenting as intractable epistaxis over a period of 4 years. Out of these 14 patients, only 6 had ICA pseudoaneurysms, and the rest were in relation to ECA. All these patients were managed with endovascular procedures. The parent artery was occluded in 3 patients and pseudoaneurysm coiling was done in the other three. One patient developed recurrence of symptoms and required a second intervention.

Ronchetti et al. (26) described a case of cavernous ICA aneurysm with sphenoid sinus extension, presenting with epistaxis. ICA occlusion test showed little cross-flow, contraindicating the occlusion of the aneurysm parent vessel. Multiple trials of coiling the aneurysm with coils and flow diverter stents were done but the aneurysm recanalized after every attempt and the patient died of intractable epistaxis. They concluded that covered stents are difficult to be deployed in such cases, and coiling and flow-diverter stents are unlikely to achieve complete aneurysm exclusion. When ICA occlusion is not feasible, in addition to endovascular coiling, sphenoid sinus storage with wrapping of the aneurysm should be attempted.

\section{CONCLUSIONS}

Epistaxis is a common ailment, but not all episodes are self-limiting. Rarely ICA aneurysms can erode the thin bone separating the ICA from the sphenoid sinus cavity leading to life-endangering epistaxis. Two of our patients presented following trauma to otolaryngologists, who thought them to be harboring some sinonasal malignancy and the patients were subjected to transnasal biopsy leading to intractable epistaxis. IADSA is the modality of choice for making a diagnosis. Trapping of the aneurysm is a safe option if there is good cross circulation.

\section{- REFERENCES}

1. Auyeung KM, Lui WM, Chow LC, Chan FL: Massive epistaxis related to petrous carotid artery pseudoaneurysm after radiation therapy: Emergency treatment with covered stent in two cases. AJNR Am J Neuroradiol 24:1449-1452, 2003

2. Banfield GK, Brasher PF, Deans JA, Barker PG, Taylor WJ: Intrapetrous carotid artery aneurysm presenting as epistaxis and otalgia. J Laryngol Otol 109:865-867, 1995
3. Bavinzski G, Killer M, Knosp E, Ferraz-Leite H, Gruber A, Richling B: False aneurysms of the intracavernous carotid artery--report of 7 cases. Acta Neurochir (Wien) 139:37-43, 1997

4. Bhatoe HS, Suryanarayana KV, Gill HS: Recurrent massive epistaxis due to traumatic intracavernous internal carotid artery aneurysm. J Laryngol Otol 109:650-652, 1995

5. Brodsky A, Luntz M, Veller B, Sharf B, Goldsher M, Lurie MMiselevich I: Intrasphenoid mycotic aneurysm of the internal carotid artery. Otolaryngol Head Neck Surg 128:887-890, 2003

6. Chaboki H, Patel AB, Freifeld S, Urken ML, Som PM: Cavernous carotid aneurysm presenting with epistaxis. Head Neck 26:741-746, 2004

7. Chen D, Concus AP, Halbach VV, Cheung SW: Epistaxis originating from traumatic pseudoaneurysm of the internal carotid artery: Diagnosis and endovascular therapy. Laryngoscope 108:326-331, 1998.

8. Davies A, Dale O, Renowden S: Spontaneous rupture of an intra-cavernous internal carotid artery aneurysm presenting with massive epistaxis. J Laryngol Otol 125:1070-1072, 2011

9. Eckert B, Thie A, Carvajal M, Groden C, Zeumer H: Predicting hemodynamic ischemia by transcranial Doppler monitoring during therapeutic balloon occlusion of the internal carotid artery. AJNR Am J Neuroradiol 19:577-582, 1998

10. Goleas J, Mikhael MA, Paige ML, Wolff AP: Intracavernous carotid artery aneurysm presenting as recurrent epistaxis. Ann Otol Rhinol Laryngol 100:577-579, 1991

11. Halbach VV, Higashida RT, Dowd CF, Urwin RW, Balousek PA, Lempert TE, Hieshima GB: Cavernous internal carotid artery aneurysms treated with electrolytically detachable coils. J Neuroophthalmol 17:231-239, 1997

12. Han MH, Sung MW, Chang KH, Min YG, Han DH, Han MC: Traumatic pseudoaneurysm of the intracavernous ICA presenting with massive epistaxis: Imaging diagnosis and endovascular treatment. Laryngoscope 104:370-377, 1994

13. Honeybul S, Barker S, Poitelea C, Ditchfield A: Multiple intracranial aneurysms presenting with epistaxis. J Clin Neurosci. 13:394-397, 2006

14. Karamoskos $P$, Dohrmann PJ: Traumatic internal carotid artery aneurysm and massive epistaxis. Aust N Z J Surg 59:745-747, 1989

15. Kim JY, Farkas J, Putman CM, Varvares M: Paraclinoid internal carotid artery aneurysm presenting as massive epistaxis. Ann Otol Rhinol Laryngol 109:782-786, 2000

16. Lehmann P, Saliou G, Page C, Balut A, Le Gars D, Vallee JN: Epistaxis revealing the rupture of a carotid aneurysm of the cavernous sinus extending into the sphenoid: treatment using an uncovered stent and coils. Review of literature. Eur Arch Otorhinolaryngol 266:767-772, 2009

17. Lempert TE, Halbach VV, Higashida RT, Dowd CF, Urwin RW, Balousek PA, Hieshima GB: Endovascular treatment of pseudoaneurysms with electrolytically detachable coils. AJNR Am J Neuroradiol 19:907-911, 1998

18. Maldonado-Naranjo A, Kshettry VR, Toth G, Bain M: Nontraumatic superior hypophyseal aneurysm with associated pseudoaneurysm presenting with massive epistaxis. Clin Neurol Neurosurg 115:2251-2253, 2013 
19. Monux A, Tomas M, Kaiser C, Gavilan J: Conservative management of epistaxis. J Laryngol Otol 104:868-870, 1990

20. Moreau S, De Rugy MG, Babin E, Courtheoux P, Valdazo A: Supraselective embolization in intractable epistaxis: Review of 45 cases. Laryngoscope 108:887-888, 1998

21. Moro $\mathrm{Y}$, Kojima $\mathrm{H}$, Yashiro $\mathrm{T}$, Moriyama $\mathrm{H}$ : A case of internal carotid artery aneurysm diagnosed on basis of massive nosebleed. Auris Nasus Larynx 30:97-102, 2003

22. Pathak PN: Epistaxis--due to ruptured aneurysm of the internal carotid artery. J Laryngol Otol 86:395-397, 1972

23. Quintana F, Diez C, Gutierrez A, Diez ML, Austin O, Vazquez A: Traumatic aneurysm of the basilar artery. AJNR Am J Neuroradiol 17:283-285, 1996

24. Radkowski D, McGill TJ, Healy GB, Jones DT: Penetrating trauma of the oropharynx in children. Laryngoscope 103:991994, 1993
25. Renn $\mathrm{WH}$, Rhoton AL Jr: Microsurgical anatomy of the sellar region. J Neurosurg 43:288-298, 1975

26. Ronchetti G, Panciani PP, Cornali C, Mardighian D, Villaret AB, Stefini R, Fontanella MM, Gasparotti R: Ruptured aneurysm in sphenoid sinus: Which is the best treatment? Case Rep Neurol 5:1-5, 2013

27. Roopesh Kumar VR, Madhugiri VS, Sasidharan GM, Gundamaneni SK: Giant cavernous carotid artery aneurysm mimicking a fungal granuloma and presenting with massive epistaxis. BMJ Case Rep 2012:2012 pii: bcr2012006876. doi: 10.1136/bcr-2012-006876

28. Zhang C, Xie X, You C, Mao B, Wang C, He M, Sun H: Endovascular treatment of traumatic pseudoaneurysm presenting as intractable epistaxis. Korean J Radiol 11:603611,2010 